\title{
Stoichiometry and disorder influence over electronic structure in nanostructured $\mathrm{VO}_{\mathrm{x}}$ films
}

\author{
A. D'Elia • S. J. Rezvani • N. Zema • F. Zuccaro • \\ M. Fanetti • B. Belec • B. W. Li • C. W. Zou • \\ C. Spezzani • M. Sacchi • A. Marcelli • M. Coreno
}

Received: 28 July 2020 / Accepted: 21 December 2020 / Published online: 30 January 2021

(C) The Author(s) 2021

\begin{abstract}
We present and discuss the role of nanoparticles size and stoichiometry over the local atomic environment of nanostructured $\mathrm{VO}_{\mathrm{x}}$ films. The samples have been characterized in situ using X-ray absorption nearedge structure (XANES) spectroscopy identifying the stoichiometry-dependent fingerprints of disordered atomic arrangement. In vanadium oxides, the ligand atoms arrange according to a distorted octahedral geometry depending on the oxidation state, e.g. trigonal distortion in $\mathrm{V}_{2} \mathrm{O}_{3}$ and tetragonal distortion in bulk $\mathrm{VO}_{2}$. We demonstrate, taking $\mathrm{VO}_{2}$ as a case study, that as a
\end{abstract}

\footnotetext{
A. D’Elia $(\bowtie)$

II Physikalisches Institut, Universität zu Köln, Zülpicher Straße 77, 50937 Köln, Germany

e-mail: delia@ph2.uni-koeln.de
}

A. D'Elia · S. J. Rezvani

Laboratorio TASC, IOM-CNR, Basovizza SS-14, km 163.5, 34149 Trieste, Italy

\section{S. J. Rezvani · A. Marcelli}

Laboratori Nazionale di Frascati, INFN, Via Enrico Fermi 54, Frascati, Italy

\section{N. Zema}

ISM-CNR, Istituto Struttura della Materia, Area della Ricerca di Tor Vergata, Via del Fosso del Cavaliere, Rome, Italy

F. Zuccaro · A. Marcelli $\cdot$ M. Coreno ISM-CNR, Istituto Struttura della Materia, LD2 Unit, Basovizza Area Science Park, 34149 Trieste, Italy consequence of the nanometric size of the nanoparticles, the original ligands symmetry of the bulk is broken resulting in the coexistence of a continuum of distorted atomic conformations. The resulting modulation of the electronic structure of the nanostructured $\mathrm{VO}_{\mathrm{x}}$ as a function of the oxygen content reveals a stoichiometry-dependent increase of disorder in the ligands matrix. This work shows the possibility to produce $\mathrm{VO}_{\mathrm{x}}$ nanostructured films accessing new disordered phases and provides a unique tool to investigate the complex matter.

M. Fanetti $\cdot$ B. Belec

Materials Research Laboratory, University of Nova Gorica,

Vipavska 11c, SI-5270 Ajdovščina, Slovenia

B. W. Li • C. W. Zou

National Synchrotron Radiation Laboratory, University of Science and Technology of China, Hefei 230029, People's Republic of China

C. Spezzani

Elettra-Sincrotrone Trieste, I-34149 Basovizza, Italy

M. Sacchi

Synchrotron SOLEIL, L'Orme des Merisiers, Saint-Aubin, BP 48, 91192 Gif-sur-Yvette Cedex, France

M. Sacchi

Institut des NanoSciences de Paris, Sorbonne Université, CNRS UMR 7588, 4 Place Jussieu, 75005 Paris, France

A. Marcelli

Rome International Centre for Material Science Superstripes, RICMASS, Via dei Sabelli 119A, 00185 Rome, Italy 
Keywords Disordered materials · Nanostructured vanadium oxides $\cdot$ Distorted ligand environment . $\mathrm{XANES} \cdot \mathrm{VO}_{\mathrm{x}}$

\section{Introduction}

Vanadium oxides have been studied extensively due to their various possible stoichiometric phases characterized by different oxidation states, from $\mathrm{V}^{+2}$ to $\mathrm{V}^{+5}$ as well as mixed-valence oxides (Magneli and Wadsley series) (Schwingenschlögl and Eyert 2004; Chen et al. 2019) which provides an equally large variety of electronic and physico-chemical properties. For instance, $\mathrm{V}_{2} \mathrm{O}_{5}$ and $\mathrm{V}_{6} \mathrm{O}_{13}$ have been investigated for possible applications as cathode material in Li-ion batteries (Chan et al. 2007; Xu et al. 2016; Shi et al. 2018; Xiao and Zhang 2018; Tan et al. 2018). Vanadium oxides also bear the seed of a strong electronic correlation. $\mathrm{VO}_{2}, \mathrm{~V}_{2} \mathrm{O}_{3}$ and the mixed-valence $\mathrm{V}_{n} \mathrm{O}_{2 n-1}(n=3-6$, 8 and 9) systems all exhibit first-order metal-insulator transitions (MIT) characterized by a nanoscale phase separation (Marcelli et al. 2017; McLeod et al. 2017), which can be exploited in the emerging field of Mottronics (Brahlek et al. 2017). Nevertheless, tuning the properties of vanadium oxides during the early synthesis stages is a difficult task, due to the complex interplay among stoichiometry, lattice order and size of the sample.

The control of the lattice order is one of the most used tools to modulate the electronic structure of matter (Fan et al. 2014; Pinto et al. 2018a; Rezvani et al. 2016a; Rezvani et al. 2018; D’Elia et al. 2020a). However, while methods to slightly modify the inter-atomic distances, e.g. application of epitaxial strain, are widely used, the development of a technique able to produce disordered samples with controllable stoichiometry is in its early stage despite its potential.

It has been shown that the amorphous $\mathrm{VO}_{x}$ exhibits superior intercalation properties with respect to the crystalline counterpart due to the large number of the dangling bond within the defective structure revealing their technological appeal (Uchaker et al. 2014; Chae et al. 2014; Wu et al. 2018).

Disordered $\mathrm{VO}_{x}$ could benefit from reducing their size to the nanoscale (Jagiello et al. 2017; Pasqualini et al. 2017; Sartale et al. 2013) because of confinement effects over the electronic structure, e.g. quantum confinement enhancement of the work function (D'Elia et al. 2020b; Zhou and Zachariah 2012), and because of a large effective surface area (Rezvani et al. 2016b; Pinto et al. 2016; Pinto et al. 2018b).

The possibility to produce disordered nanostructured (NS), i.e. assembled by nanoparticles, $\mathrm{VO}_{x}$ films and to monitor in situ their local atomic arrangement is therefore of great interest.

In the present work, we present an in situ X-ray absorption near-edge structure (XANES) spectroscopy investigation of $\mathrm{NS} \mathrm{VO}_{x}$ with tunable stoichiometry.

XANES is associated with the electronic transitions from core shells to unoccupied states following a photoabsorption process, possessing the unique capability to probe concurrently the stoichiometry and local structure of the sample (Bachrach 1992; Bianconi 1982). The fabricated films have been characterized at distinct oxygen concentration stages monitoring the evolution of the electronic structure as a function of stoichiometry.

The fingerprints of a disordered ligands arrangement have been observed and are discussed comparing our data with those of a crystalline samples and with several simulations linking the coexistence of multiple randomly distributed atomic dislocations, with surface area and nanoparticle size.

\section{Experimental}

The NS $\mathrm{VO}_{x}$ films were deposited using a combination of the Pulsed Micro-plasma Cluster Source (PMCS) and the Supersonic Cluster Beam Deposition (SCBD) method. SCBD is a well-known synthesis method able to produce cluster assembled NS materials (D'Elia et al. 2020b; Borghi et al. 2018; Barborini et al. 2011). This method offers considerable advantages for neutral cluster manipulation based on effusive beams making the seeded supersonic beam approach very powerful for the deposition of NS films. PMCS is a cluster source characterized by high deposition rate, control over cluster growth and landing energy of the cluster beam (Wegner et al. 2006; Piseri et al. 2004; Barborini et al. 1999). Combining SCBD and PMCS is an original approach to the preparation of disordered NS vanadium oxide films, which facilitated their in situ characterization by XANES spectroscopy.

The PMCS is a pulsed-cluster source driven by a high-power pulsed electric discharge. A vanadium cathode (6 mm diam. rod, purity $99.9 \%$, EvoChem $\mathrm{GmbH}$ ) was used to generate a seeded supersonic beam of 
vanadium oxide clusters. To oxidize the nanoparticles in the early synthesis stage, an $\mathrm{Ar}-\mathrm{O}_{2}$ gas mixture (high purity Ar: $99.9995 \%$, SIAD) with a controlled quantity of oxygen was used. In the experimental layout, the supersonic cluster beam produced by the PMCS is deposited in situ on a copper substrate, which is electrically isolated from the rest of the experimental chamber. The base pressure of the experimental chamber was $1 \times$ $10^{-9}$ mbar, while operating the PMCS, raised it to $\sim 5$ $\times 10^{-9}$ mbar due to the carrier gas injected by the cluster source.

To synthesize samples with different stoichiometry, we fed the PMCS with an Ar- $\mathrm{O}_{2}$ gas mixture with an $\mathrm{O}_{2}$ molar percentage in the range of $0-1.25 \%$. The working parameters of the PMCS have been adjusted to maximize the deposition rate. The delay between the gas injection and the discharge firing was $0.51-0.64 \mathrm{~ms}$; the discharge operating voltage was $0.9 \mathrm{kV}$, and the discharge duration was $60 \mu \mathrm{s}$; the pulsed-valve aperture was between 196 and $220 \mu \mathrm{s}$; and the pulse repetition rate was $3 \mathrm{~Hz}$, and the $\mathrm{Ar}-\mathrm{O}_{2}$ pressure feeding the Parker valve was $60 \mathrm{bar}$. All the samples have been synthesized using Ar or Ar- $\mathrm{O}_{2}$ gas mixture as specified elsewhere (D'Elia et al. 2020b). The substrate was kept at $\sim 300 \mathrm{~K}$ during the deposition, and the deposited films have been studied in situ using XANES spectroscopy. The UHV chamber has been coupled to the PMCS, available at the TASC laboratory (De Simone et al. 2012) and equipped with an XYZ manipulator as depicted in Fig. 1. The XANES measurements have been performed at the Circular Polarization beamline of the Elettra synchrotron radiation facility using the CryoAlp UHV experimental chamber (Marcelli et al. 2018). Total electron yield (TEY) spectra have been acquired measuring the drain current, connecting the sample to ground through a Keithley 486 picoammeter (see Fig. 1). The sample was kept normal to the cluster beam, while the angle between the incident photons and the sample surface was $45^{\circ}$.

Furthermore, ex situ XANES measurements on crystalline sample, synthesized by molecular beam epitaxy (Fan et al. 2014), were performed using the IRMA experimental chamber (Sacchi et al. 2003) and used as a reference in our experiment. All the XANES spectra have been normalized to the incident photon flux and keeping the substrate temperature at $\sim 300 \mathrm{~K}$. The morphology and the size of the clusters have been analysed also by transmission electron microscopy (TEM) using a $200 \mathrm{kV}$ field-emission microscope (JEM2100F-UHR, JEOL).

\section{Results and discussion}

The morphology and size of nanoparticles deposited by SCBD have been investigated using TEM. A deposition of $1 \mathrm{~s}$ has been performed on a TEM grid with an amorphous $\mathrm{C}$ supporting film. Figure 2 shows the TEM image of the $\mathrm{VO}_{2.5}$ sample. Although the individual nanoparticles form large agglomerates, they remain distinctly visible in the magnified image. Despite the aggregation that hampers the size distribution assessment, the size of the nanoparticles can be estimated to be in the range 3-6 nm with an average value of $\sim 4.4 \mathrm{~nm}$.

No clear differences in the particle size distribution have been observed as a function of carrier gas and oxidation state.

The different NS VOx films have been deposited and investigated in situ using XANES spectroscopy at V $\mathrm{L}_{2,3}$ and $\mathrm{O} \mathrm{K}$ edges. All the deposited films have a thickness of at least $15 \mathrm{~nm}$ in order to avoid probing the $\mathrm{Cu}$ substrate. We identify the different $\mathrm{VO}_{x}$ samples using the stoichiometric ratio defined as $x=[$ No. O atoms/No. $\mathrm{V}$ atoms], in the range $0 \leq x \leq 2.5$. The XANES spectra for different $\mathrm{VO}_{x}$ samples are shown in Fig. 3.

The vanadium L-edges spectra show two major components at $\sim 515.2 \mathrm{eV}$ (a) and $\sim 522.3 \mathrm{eV}$ (b) (see left panel of Fig. 3). We observe a chemical shift towards the higher photon energies with the introduction of the oxygen into the structure for values as low as $x=0.3$.

The O K-edge spectra of the $\mathrm{VO}_{x}$ samples (Fig. 3 right panel), reveal a significant evolution of the electronic structure with stoichiometry which can be understood in terms of crystal field splitting and metal-ligand hybridization. In $\mathrm{VO}_{x}, \mathrm{O}$ atoms arrange in an octahedral geometry generating a cubic crystal field (Hermann and Witko 2001; De Groot et al. 1989), which splits the degenerate $3 d$ manifold into $t_{2 g}$ and $e_{g}$ levels. As shown in Fig. 3, the $\mathrm{O} \mathrm{K}$ edge XANES exhibits two main contributions at $\sim 530$ and $\sim 532.5 \mathrm{eV}$, which can be associated with $t^{*}{ }_{2 g}$ and $\mathrm{e}^{*}{ }_{g}$ states, respectively (De Groot et al. 1989). Their relative intensity shows a marked dependence on the oxidation state.

Since XANES probes the empty density of states (DOS), $t^{*}{ }_{2 g}$ and $\mathrm{e}^{*}{ }_{g}$ signals can be observed at the $\mathrm{O} \mathrm{K}$ edge only when $\mathrm{t}_{2 g}$ and $\mathrm{e}_{g}$ electrons are bound with the O $2 p$ electrons. The presence of $t^{*}{ }_{2 g}$ in $\mathrm{VO}_{0.6}$ samples (the weak component around $530 \mathrm{eV}$ ) can be attributed to the hybridization of $\mathrm{V}-3 d$ and $\mathrm{O}-2 p$ electrons in agreement with a previous Auger investigation, which 
Fig. 1 Layout of the experimental setup including the cluster beam and the TEY acquisition scheme. A copper substrate is positioned normal to the cluster beam and at $45^{\circ}$ with respect to the incident X-ray beam. The X-ray induced electron yield is measured by collecting the drain current via the copper substrate

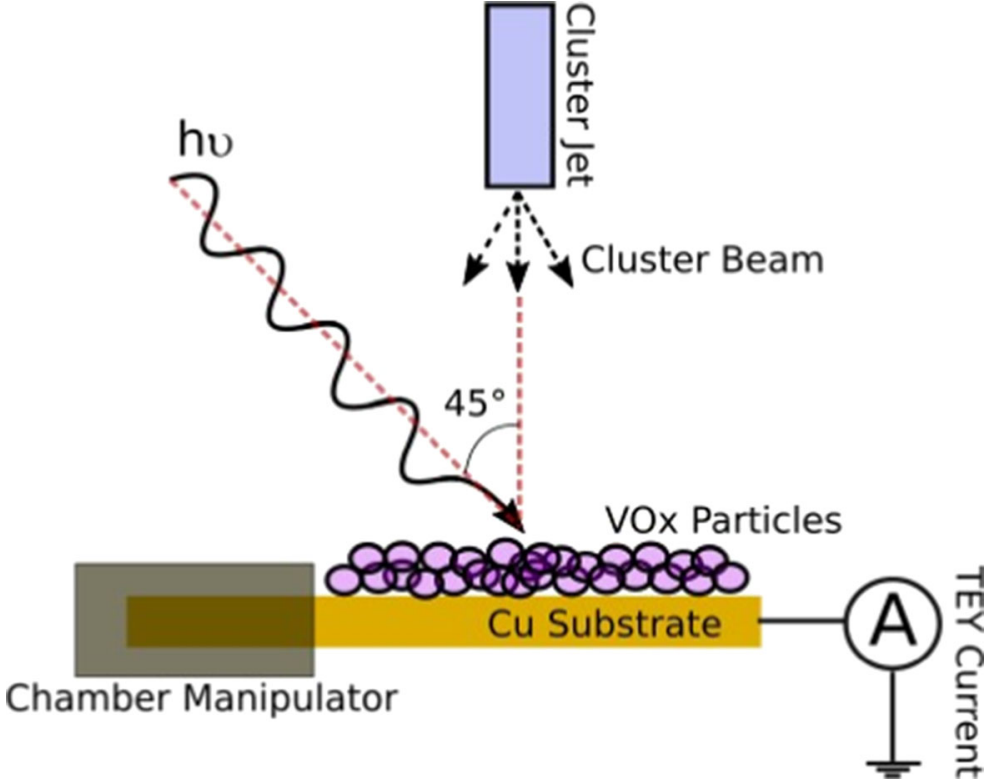

predicts a mixed $4 s-3 d$ valence band for this suboxide (D'Elia et al. 2020b). $\mathrm{e}^{*}$ and $t^{*}{ }_{2 g}$ features are observable on the whole $\mathrm{VO}_{x}$ set, even though they are broad and not well separated.

The origin of $\mathrm{e}^{*} g$ and $t^{*}{ }_{2 g}$ width and energy separation can be interpreted by comparison with a reference single crystal (SC) sample. We investigated
$\mathrm{VO}_{2}$ as a case study. The comparison of the $\mathrm{SC}-\mathrm{VO}_{2}$ and NS- $\mathrm{VO}_{2}$ is reported in Fig. 4.

In the SC sample spectra, the $\mathrm{e}^{*}$ and $t^{*}{ }_{2 g}$ features are well separated pointing to a strong and homogeneous crystal field and therefore to a locally ordered atomic environment. The $\mathrm{e}^{*}$ and $t^{*}{ }_{2 g}$ features of the NS film, on the other hand, are broadened and less resolved. The $t^{*}{ }_{2 g}$
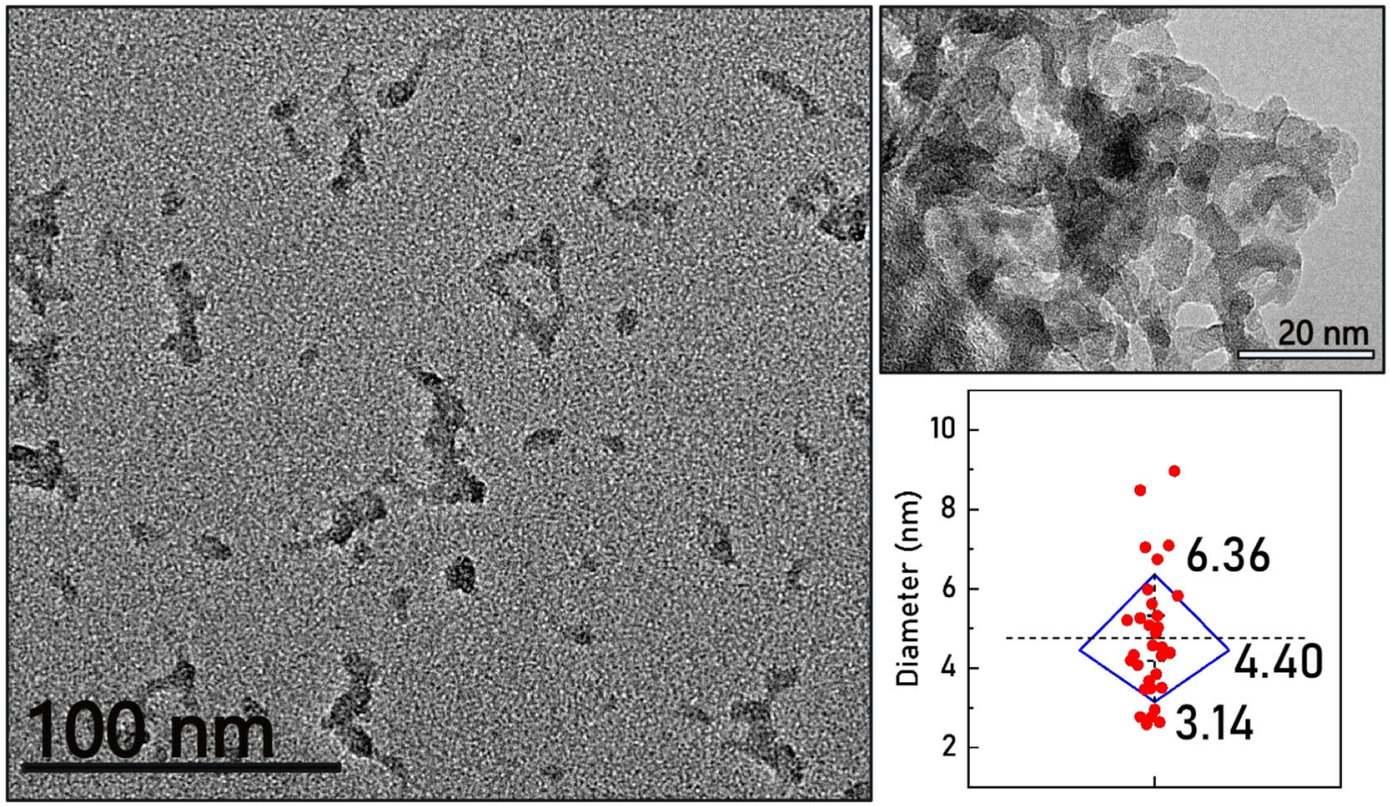

Fig. 2 TEM image of the nanoparticle aggregates for $\mathrm{VO}_{2.5}$ along with the size distribution of the particles. The particles show a size distribution between $\sim 3$ and $\sim 6 \mathrm{~nm}$ with an average value of $\mathrm{d}=4.4 \mathrm{~nm}$ 
Fig. 3 Left: XANES spectra of different $\mathrm{VO}_{\mathrm{x}}$ films at the $\mathrm{V} \mathrm{L}_{2,3}$ edges and the $\mathrm{O}$ K-edge. Right: Comparison of the $\mathrm{O} \mathrm{K}$-edge XANES spectra of $\mathrm{VO}_{\mathrm{x}}$ samples

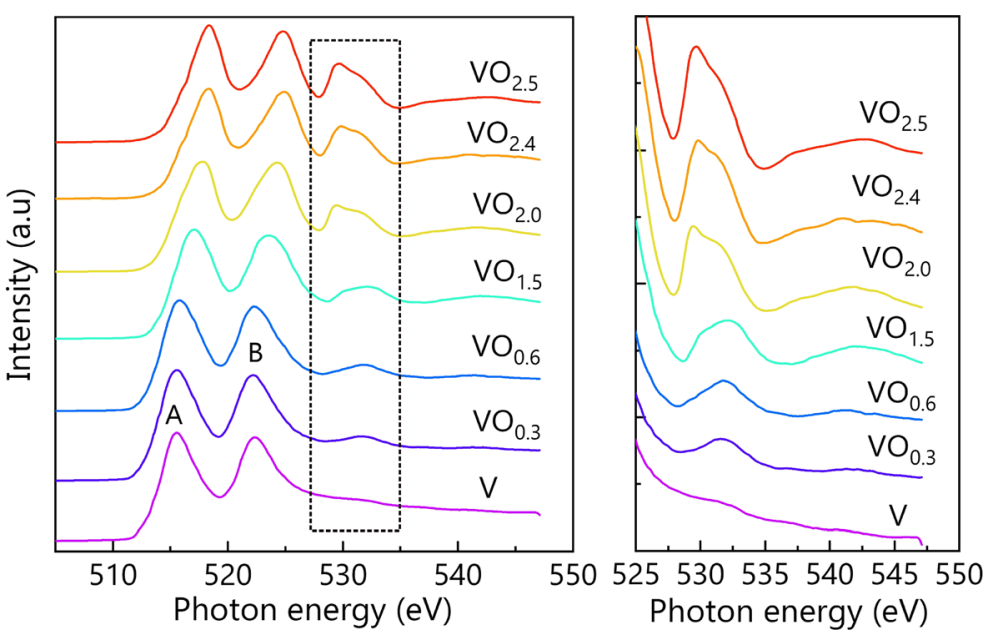

energy position seems unaffected within our experimental resolution, while the $\mathrm{e}^{*}{ }_{g}$ component is red-shifted of about $0.4 \mathrm{eV}$. Coherently, a red-shift of the $\mathrm{L}_{3}$ energy position is observed in the NS sample with respect to the SC since V L edges are particularly sensitive to the $\mathrm{e}^{*}{ }_{g}$ contribution to the empty DOS (Zaanen et al. 1985; Abbate et al. 1991).

The observed $\mathrm{e}^{*}$ red-shift in the NS- $\mathrm{VO}_{2}$ is possibly due to the presence of Jahn-Teller-like distortions of the oxygen octahedron matrix which directly influences the electronic structure of the NS sample (Kasatikov et al. 2019; Ruzmetov et al. 2007). In the extreme case, a high number (ideally infinite) of different ligand distortions coexist within

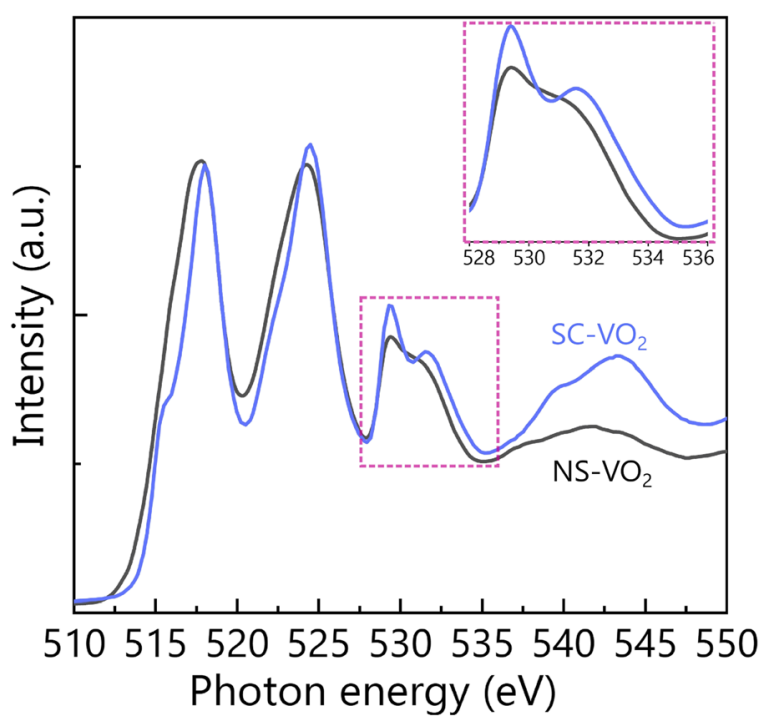

Fig. 4 Comparison between the $\mathrm{O} \mathrm{K}$ edge of the $\mathrm{NS}_{\mathrm{VO}_{2}}$ film and that of a single crystalline (SC) film a disordered material. The disorder considered here is of geometric nature; around each metal site, the local symmetry of the ligands arrangement is broken because of random atomic dislocations, i.e. displacements from their symmetry site. In this picture, each vanadium site is surrounded by a different distorted ligand conformation which leads to an overall disordered structure.

In order to confirm this observation, and since the $\mathrm{e}^{*}{ }_{g}$ orbitals are the most involved, we investigated $\mathrm{V} \mathrm{L}$ edges line shape of the $\mathrm{NS} \mathrm{VO}_{2}$ sample (Zaanen et al. 1985; Kasatikov et al. 2019). Several simulations were carried out within the charge transfer multiplet framework to investigate possible distortions effect on the $\mathrm{VO}_{2}$ electronic structures. The calculations were performed by the configuration interaction cluster for octahedral and distorted $\mathrm{VO}_{2}$ structures (see Fig. 5). The refinement of the analysis of the distorted structures was performed, employing the CTM4XAS (Stavitski and de Groot 2010) simulation code.

According to previously published work (Ikeno et al. 2011), the calculations were based on a crystal field $10 \mathrm{Dq}=2.35 \mathrm{eV}$ with $80 \%$ reduction of the Slater integrals and an average Coulomb interaction $U_{\mathrm{dd}}-U_{\mathrm{pd}}$ of $0.88 \mathrm{eV}$. Finally, an overall broadening of $0.35 \mathrm{eV}$ full width was applied.

In $\mathrm{VO}_{2}$ the oxygen atoms are arranged according to a tetragonally distorted octahedral geometry (D'Elia et al. $2020 \mathrm{a}, \mathrm{c})$. The tetragonal distortion leads to a further splitting of the $t^{*}{ }_{2 g}$ and $\mathrm{e}^{*}$ orbitals resulting in the four levels $\mathrm{e}^{*}, \mathrm{~b}^{*}{ }_{2 g}, \mathrm{a}^{*}{ }_{1 g}$ and $\mathrm{b}^{*}{ }_{1 g}$ (see Fig. 5 right panel). The $\mathrm{e}_{g}, \mathrm{~b}_{2 g}$, separation is called $\mathrm{Q}_{1}$, while the $\mathrm{a}_{1 g}$ and $\mathrm{b}_{1 g}$ are splitted by $\mathrm{Q}_{2}$. To mimic the ligand atomic 
Fig. 5 Left: simulated V L edges spectra of $\mathrm{VO}_{2}$ for different Q2 energy splitting values and NS $\mathrm{VO}_{2}$ measured spectrum (black) Right: schematic representation of the energy levels splitting passing from $\mathrm{O}_{\mathrm{h}}$ to $\mathrm{D}_{4 \mathrm{~h}}$ symmetry

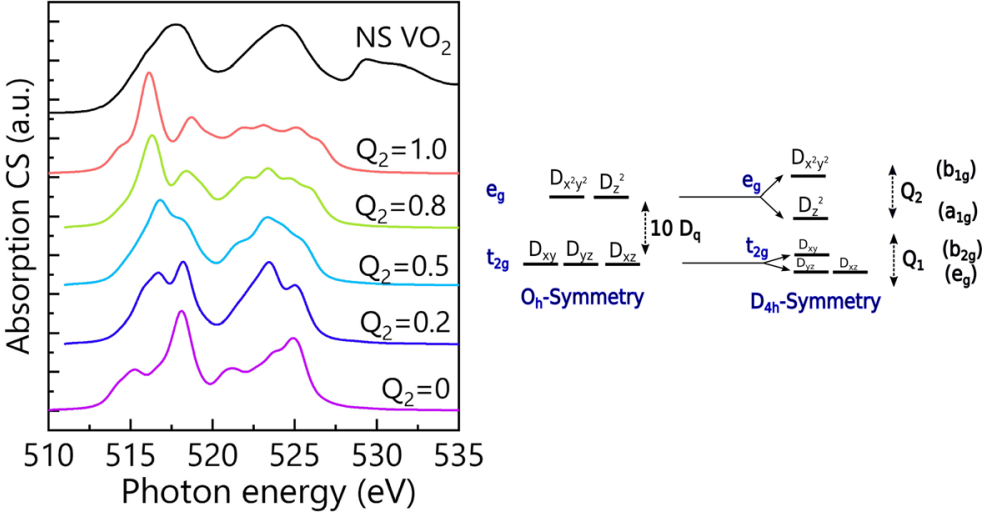

dislocations, e.g. the bending of two opposite octahedron vertices which red-shift the $\mathrm{e}_{g}{ }_{g}$, the calculations were performed for increasing values of $\mathrm{Q}_{2}=0.2,0.5$, 0.8 and $1.0 \mathrm{eV}$ while keeping $\mathrm{Q}_{1}=0.2 \mathrm{eV}$. The choice to keep the $\mathrm{Q}_{1}$ constant is justified by considering the prominent sensitivity of $\mathrm{V} \mathrm{L}$ edges to the $\mathrm{e}^{*}$ orbitals which hide small spectral changes in the $t^{*}{ }_{2 g}$ energy region (Zaanen et al. 1985). We compare the simulated

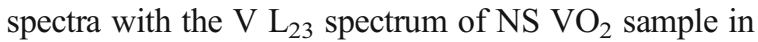
Fig. 5.

The results demonstrate that the observed $\mathrm{e}^{*}$ redshift in our sample is mainly due to the presence of distorted ligand environment and that simulations with $\mathrm{Q}_{2}=0.2 \mathrm{eV}$ and $0.5 \mathrm{eV}$ match better the experimental data.

However, the experimental spectrum shows features of distinct distorted states. Since the geometrical distortion of the oxygen octahedron matrix reflects atomic disloca-

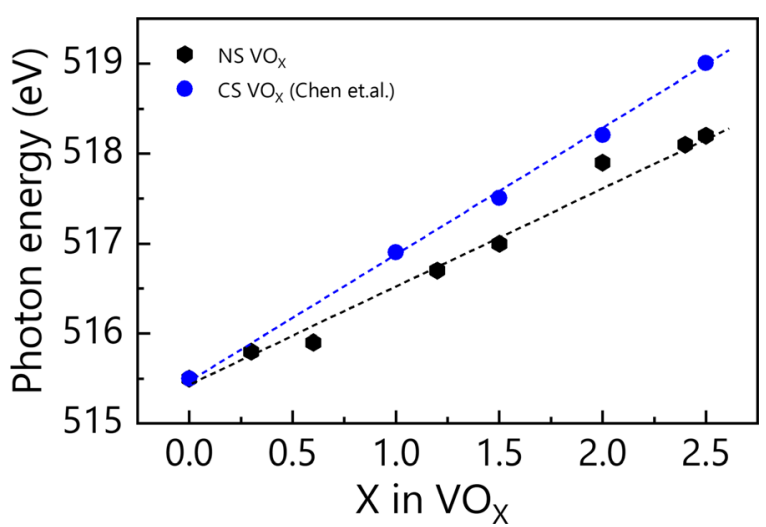

Fig. 6 Comparison between the $\mathrm{V} \mathrm{L}_{3}$ energy position as a function of stoichiometry for the NS VOx film (black) and crystalline samples data (blue) found in literature (Chen et al. 1994) tions, i.e. displacements, from the ordered atomic arrangement, the results displayed in Fig. 5 point to the coexistence of a multitude of distorted ligand conformations.

The cause of the disordered nature of our samples can be identified in the small size of the nanoparticles. The finite dimensions of the NS films constituents and their irregular shape (see Fig. 2) provide a higher surface area with respect to bulk materials, naturally leading to symmetry breaking and to the creations of random atomic dislocations.

The disorder-induced $\mathrm{L}_{3}$ red-shift with respect to the bulk samples reported for $\mathrm{VO}_{2}$ can be observed for the whole set of $\mathrm{VO}_{x}$ films.

The $\mathrm{L}_{3}$ maximum position as a function of the oxidation state is depicted in Fig. 6. The comparison with crystalline bulk samples found in literature (Chen et al. 1994) evidences a stoichiometry-dependent $\mathrm{L}_{3}$ red-shift for the whole oxygen concentration range.

This implies that the degree of disorder increases with stoichiometry which can be understood considering that to a high number of oxygen atoms corresponds a high number of achievable distorted atomic conformations. As a consequence, the highest oxidation states are most likely to assume a severely distorted atomic arrangement with respect to the samples with less oxygen.

The evidence of the disordered ligand environment for all the oxygen concentration is linked to the synthesis method and to the nucleation conditions of the nanoparticles. During the supersonic expansion of the seeded cluster beam, the thermal energy acquired during the nucleation process is converted in kinetic energy quenching the atoms in disordered conformations. This process is particularly efficient in small nanoparticles whose high surface area favours the symmetry breaking of ligand conformations. 
This demonstrates that there is a complex influence of stoichiometry and disorder in $\mathrm{VO}_{\mathrm{x}} \mathrm{NS}$ films with respect to the bulk analogue that suggest a way to tailor the electronic structure of these materials.

\section{Conclusion}

We investigated in situ NS $\mathrm{VO}_{x}$ NS films using XANES spectroscopy demonstrating that nanoparticle size and stoichiometry contribute to determine the symmetry of ligands arrangement.

We demonstrated that broad $t^{*}{ }_{2 g}$ and $\mathrm{e}^{*}{ }_{g}$ features and reduced $t^{*}{ }_{2 g}-\mathrm{e}^{*}{ }_{g}$ splitting with respect to crystalline samples represent the fingerprints of disordered ligand matrix. This is confirmed by XANES simulations that show the coexistence of multiple distorted local environments. Our results point towards a stoichiometrydependent red-shift of the $\mathrm{V} \mathrm{L}_{3}$ edge with respect to the bulk counterpart. This transfer of spectral weight towards lower photon energy is induced by the disordered structure of our samples which can be directly connected to the reduced dimension of the nanoparticles composing the films. Our study shows the complex interplay among stoichiometry, sample size and disorder in vanadium oxides and provides a tool to monitor and control the disorder in $\mathrm{NS} \mathrm{VO}_{x}$ films. Our results are of potential interest in different research area, such as Liion insertion devices, where the use of a disordered and NS material may be beneficial.

Acknowledgments The authors would like to thank D. Catone (ISM-CNR) for writing the acquisition software.

Funding Open Access funding enabled and organized by Projekt DEAL.

\section{Compliance with ethical standards}

Conflict of interest The authors declare that they have no conflict of interest.

Open Access This article is licensed under a Creative Commons Attribution 4.0 International License, which permits use, sharing, adaptation, distribution and reproduction in any medium or format, as long as you give appropriate credit to the original author(s) and the source, provide a link to the Creative Commons licence, and indicate if changes were made. The images or other third party material in this article are included in the article's Creative Commons licence, unless indicated otherwise in a credit line to the material. If material is not included in the article's Creative Commons licence and your intended use is not permitted by statutory regulation or exceeds the permitted use, you will need to obtain permission directly from the copyright holder. To view a copy of this licence, visit http://creativecommons.org/licenses/by/4.0/.

\section{References}

Abbate M, De Groot FMF, Fuggle JC et al (1991) Soft-x-rayabsorption studies of the electronic-structure changes through the $\mathrm{VO}_{2}$ phase transition. Phys Rev B 43:7263-7266. https://doi.org/10.1103/PhysRevB.43.7263

Bachrach RZ (1992) Synchrotron radiation research advances in surface and interface science. Springer US, Boston, MA

Barborini E, Piseri P, Milani P (1999) Pulsed microplasma source of high intensity supersonic carbon cluster beams. J Phys D Appl Phys 32:L105-L109. https://doi.org/10.1088/0022$3727 / 32 / 21 / 102$

Barborini E, Ducati C, Leccardi M, et al (2011) Nanostructured refractory metal oxide films produced by a pulsed microplasma cluster source as active layers in microfabricated gas sensors. Jpn J Appl Phys 50 01AK01. https://doi.org/10.1143/JJAP.50.01AK01

Bianconi A (1982) Multiplet splitting of final-state configurations in x-ray-absorption spectrum of metal $\mathrm{VO}_{2}$ : effect of corehole-screening, electron correlation, and metal-insulator transition. Phys Rev B 26:2741-2747. https://doi.org/10.1103 /PhysRevB.26.2741

Borghi F, Podestà A, Piazzoni C, Milani P (2018) Growth mechanism of cluster-assembled surfaces: from submonolayer to thin-film regime. Phys Rev Appl 9:044016. https://doi. org/10.1103/PhysRevApplied.9.044016

Brahlek M, Zhang L, Lapano J, Zhang HT, Engel-Herbert R, Shukla N, Datta S, Paik H, Schlom DG (2017) Opportunities in vanadium-based strongly correlated electron systems. MRS Commun 7:27-52. https://doi.org/10.1557 /mrc.2017.2

Chae OB, Kim J, Park I, Jeong H, Ku JH, Ryu JH, Kang K, Oh SM (2014) Reversible lithium storage at highly populated vacant sites in an amorphous vanadium pentoxide electrode. Chem Mater 26:5874-5881. https://doi.org/10.1021 /cm502268u

Chan CK, Peng H, Twesten RD, Jarausch K, Zhang XF, Cui Y (2007) Fast, completely reversible Li insertion in vanadium pentoxide nanoribbons. Nano Lett 7:490-495. https://doi. org/10.1021/nl062883j

Chen JG, Kirn CM, Frühberger B et al (1994) A NEXAFS determination of the oxidation state of vanadium carbide on $\mathrm{V}(110)$ : observation of charge transfer from vanadium to carbon. Surf Sci 321:145-155. https://doi.org/10.1016 /0039-6028(94)90035-3

Chen L, Ruan Y, Zhang G, Wei Q, Jiang Y, Xiong T, He P, Yang W, Yan M, An Q, Mai L (2019) Ultrastable and highperformance $\mathrm{Zn} / \mathrm{VO}_{2}$ battery based on a reversible singlephase reaction. Chem Mater 31:699-706. https://doi. org/10.1021/acs.chemmater.8b03409

D'Elia A, Grazioli C, Cossaro A, et al (2020a) Strain mediated filling control nature of the metal-insulator transition of $\mathrm{VO}_{2}$ 
and electron correlation effects in nanostructured films. Appl Surf Sci 148341. https://doi.org/10.1016/j. apsusc.2020.148341

D'Elia A, Cepek C, de Simone M, Macis S, Belec B, Fanetti M, Piseri P, Marcelli A, Coreno M (2020b) Interplay among work function, electronic structure and stoichiometry in nanostructured $\mathrm{VO}_{\mathrm{x}}$ films. Phys Chem Chem Phys 22: 6282-6290.https://doi.org/10.1039/d0cp00216j

D'Elia A, Rezvani SJ, Cossaro A et al (2020c) Strain induced orbital dynamics across the metal insulator transition in thin $\mathrm{VO}_{2} / \mathrm{TiO}_{2}$ (001) films. J Supercond Nov Magn 33:23832388. https://doi.org/10.1007/s10948-019-05378-0

De Groot FMF, Grioni M, Fuggle JC et al (1989) Oxygen 1s Xray-absorption edges of transition-metal oxides. Phys Rev B 40:5715-5723. https://doi.org/10.1103/PhysRevB.40.5715

De Simone M, Snidero E, Coreno M et al (2012) Oxidation of nanostructured $\mathrm{Ti}$ films produced by low energy cluster beam deposition: an X-ray photoelectron spectroscopy characterization. Thin Solid Films 520:4803-4807. https://doi. org/10.1016/j.tsf.2011.10.075

Fan LL, Chen S, Luo ZL, Liu QH, Wu YF, Song L, Ji DX, Wang P, Chu WS, Gao C, Zou CW, Wu ZY (2014) Strain dynamics of ultrathin $\mathrm{VO}_{2}$ film grown on $\mathrm{TiO}_{2}(001)$ and the associated phase transition modulation. Nano Lett 14:4036-4043. https://doi.org/10.1021/n1501480f

Hermann K, Witko M (2001) Chapter 4 Theory of physical and chemical behavior of transition metal oxides: vanadium and molybdenum oxides The Chemical Physics of Solid Surfaces 9(2001):136-198. https://doi.org/10.1016/S1571-0785(01) 80024-9

Ikeno H, Mizoguchi T, Tanaka I (2011) Ab initio charge transfer multiplet calculations on the L2,3 XANES and ELNES of 3d transition metal oxides. Phys Rev B - Condens Matter Mater Phys 83:155107. https://doi.org/10.1103/PhysRevB.83.155107

Jagiello K, Chomicz B, Avramopoulos A, Gajewicz A, Mikolajczyk A, Bonifassi P, Papadopoulos MG, Leszczynski J, Puzyn T (2017) Size-dependent electronic properties of nanomaterials: how this novel class of nanodescriptors supposed to be calculated? Struct Chem 28: 635-643. https://doi.org/10.1007/s11224-016-0838-2

Kasatikov S, Filatova E, Sakhonenkov S et al (2019) Relationship between Ta oxidation state and its local atomic coordination symmetry in a wide range of oxygen nonstoichiometry extent of $\mathrm{TaO}$ x. J Phys Chem C 123:6849-6860. https://doi. org/10.1021/acs.jpcc.8b12053

Marcelli A, Coreno M, Stredansky M, Xu W, Zou C, Fan L, Chu W, Wei S, Cossaro A, Ricci A, Bianconi A, D’Elia A (2017) Nanoscale phase separation and lattice complexity in $\mathrm{VO}_{2}$ : the metal-insulator transition investigated by XANES via auger electron yield at the vanadium L23-edge and resonant photoemission. Condens Matter 2:38. https://doi.org/10.3390 /condmat2040038

Marcelli A, Mazuritskiy MI, Dabagov SB et al (2018) A new XUV optical end-station to characterize compact and flexible photonic devices using synchrotron radiation. J Instrum 13: C03035-C03035. https://doi.org/10.1088/1748-0221/13/03 /C03035

McLeod AS, Van Heumen E, Ramirez JG et al (2017) Nanotextured phase coexistence in the correlated insulator $\mathrm{V}_{2} \mathrm{O}_{3}$. Nat Phys 13:80-86. https://doi.org/10.1038 /nphys 3882
Pasqualini M, Calcaterra S, Maroni F, Rezvani SJ, di Cicco A, Alexander S, Rajantie H, Tossici R, Nobili F (2017) Electrochemical and spectroscopic characterization of an alumina-coated $\mathrm{LiMn}_{2} \mathrm{O}_{4}$ cathode with enhanced interfacial stability. Electrochim Acta 258:175-181. https://doi. org/10.1016/j.electacta.2017.10.115

Pinto N, Rezvani SJ, Favre L, Berbezier I, Fretto M, Boarino L (2016) Geometrically induced electron-electron interaction in semiconductor nanowires. Appl Phys Lett 109:109. https://doi.org/10.1063/1.4962893

Pinto N, Caproli F, Maggioni G, Carturan S, Napoli DR (2018a) Thermally induced irreversibility in the conductivity of germanium nitride and oxynitride films. Mater Sci Semicond Process 74:57-63. https://doi.org/10.1016 /j.mssp.2017.10.006

Pinto N, Rezvani SJ, Perali A, Flammia L, Milošević MV, Fretto M, Cassiago C, de Leo N (2018b) Dimensional crossover and incipient quantum size effects in superconducting niobium nanofilms. Sci Rep 8:4710. https://doi.org/10.1038/s41598018-22983-6

Piseri P, Tafreshi HV, Milani P (2004) Manipulation of nanoparticles in supersonic beams for the production of nanostructured materials. Curr Opin Solid State Mater Sci 8:195-202. https://doi.org/10.1016/j.cossms.2004.08.002

Rezvani SJ, Pinto N, Boarino L (2018) Rapid formation of single crystalline Ge nanowires by anodic metal assisted etching Cryst Eng Comm 18(40):7843-7848. https://doi.org/10.1039 /C6CE01598K

Rezvani SJ, Pinto N, Enrico E, D’Ortenzi L, Chiodoni A, Boarino L (2016a) Thermally activated tunneling in porous silicon nanowires with embedded Si quantum dots. J Phys D Appl Phys 49:49. https://doi.org/10.1088/0022-3727/49/10 $/ 105104$

Rezvani SJ, Gunnella R, Neilson D, Boarino L, Croin L, Aprile G, Fretto M, Rizzi P, Antonioli D, Pinto N (2016b) Effect of carrier tunneling on the structure of Si nanowires fabricated by metal assisted etching. Nanotechnology 27:27. https://doi. org/10.1088/0957-4484/27/34/345301

Rezvani SJ, Pasqualini M, Witkowska A, Gunnella R, Birrozzi A, Minicucci M, Rajantie H, Copley M, Nobili F, di Cicco A (2018) Binder-induced surface structure evolution effects on Li-ion battery performance. Appl Surf Sci 435:1029-1036. https://doi.org/10.1016/j.apsusc.2017.10.195

Ruzmetov D, Senanayake SD, Ramanathan S (2007) X-ray absorption spectroscopy of vanadium dioxide thin films across the phase-transition boundary. Phys Rev B - Condens Matter Mater Phys 75:. https://doi.org/10.1103/PhysRevB.75.195102

Sacchi M, Spezzani C, Torelli P et al (2003) Ultrahigh-vacuum soft x-ray reflectometer. Rev Sci Instrum 74:2791-2795. https://doi.org/10.1063/1.1568552

Sartale SD, Ansari AA, Rezvani SJ (2013) Influence of Ti film thickness and oxidation temperature on $\mathrm{TiO} 2$ thin film formation via thermal oxidation of sputtered Ti film. Mater Sci Semicond Process 16:2005-2012. https://doi.org/10.1016/j. mssp.2013.07.006

Schwingenschlögl U, Eyert V (2004) The vanadium Magnéli phases $\mathrm{V}_{\mathrm{n}} \mathrm{O}_{2 \mathrm{n}-1}$. Ann Phys 13:475-510. https://doi. org/10.1002/andp.200410099

Shi X, Du J, Jones TGJ et al (2018) Understanding the mechanism for capacity decay of $\mathrm{V}_{6} \mathrm{O}_{13}$-based lithium-metal polymer 
batteries. ACS Appl Mater Interfaces 10:29667-29674. https://doi.org/10.1021/acsami.8b10629

Stavitski E, de Groot FMF (2010) The CTM4XAS program for EELS and XAS spectral shape analysis of transition metal L edges. Micron 41:687-694. https://doi.org/10.1016/j. micron.2010.06.005

Tan S, Jiang Y, Wei Q, Huang Q, Dai Y, Xiong F, Li Q, An Q, Xu X, Zhu Z, Bai X, Mai L (2018) Multidimensional synergistic nanoarchitecture exhibiting highly stable and ultrafast sodium-ion storage. Adv Mater 30:1707122. https://doi. org/10.1002/adma.201707122

Uchaker E, Zheng YZ, Li S, Candelaria SL, Hu S, Cao GZ (2014) Better than crystalline: amorphous vanadium oxide for sodium-ion batteries. J Mater Chem A 2:18208-18214. https://doi.org/10.1039/c4ta03788j

Wegner K, Piseri P, Tafreshi HV, Milani P (2006) Cluster beam deposition: a tool for nanoscale science and technology. J Phys D Appl Phys 39:R439-R459. https://doi.org/10.1088 /0022-3727/39/22/R02

Wu H, Qin M, Wang W, Cao Z, Liu Z, Yu Q, Lao C, Zhang D, Jia B, He D, Liu T, Volinsky AA, Cao P, Qu X (2018) Ultrafast synthesis of amorphous $\mathrm{VO}_{\mathrm{x}}$ embedded into $3 \mathrm{D}$ strutted amorphous carbon frameworks-short-range order in dual- amorphous composites boosts lithium storage. J Mater Chem A 6:7053-7061. https://doi.org/10.1039/c8ta00654g

Xiao B, Zhang B, Tang L bo, et al (2018) $\mathrm{V}_{2} \mathrm{O}_{3} / \mathrm{rGO}$ composite as a potential anode material for lithium ion batteries. Ceram Int 44:15044-15049. https://doi.org/10.1016/j. ceramint.2018.05.134

Xu N, Ma X, Wang M, Qian T, Liang J, Yang W, Wang Y, Hu J, Yan C (2016) Stationary full Li-ion batteries with interlayerexpanded $\mathrm{V}_{6} \mathrm{O}_{13}$ cathodes and lithiated graphite anodes. Electrochim Acta 203:171-177. https://doi.org/10.1016/j. electacta.2016.04.044

Zaanen J, Sawatzky GA, Fink J et al (1985) L2,3 absorption spectra of the lighter 3d transition metals. Phys Rev B 32: 4905-4913. https://doi.org/10.1103/PhysRevB.32.4905

Zhou L, Zachariah MR (2012) Size resolved particle work function measurement of free nanoparticles: aggregates vs. spheres. Chem Phys Lett 525-526:77-81. https://doi. org/10.1016/j.cplett.2011.11.045

Publisher's note Springer Nature remains neutral with regard to jurisdictional claims in published maps and institutional affiliations. 